\title{
$\cos -3267-4$
}

NINETEEN PARACENTRIC CHROMOSOMAL INVERSIONS IN MICE

Thomas H. Roderick and Norman L. Hawes

The Jackson Laboratory, Bar Harbor, Maine 04609

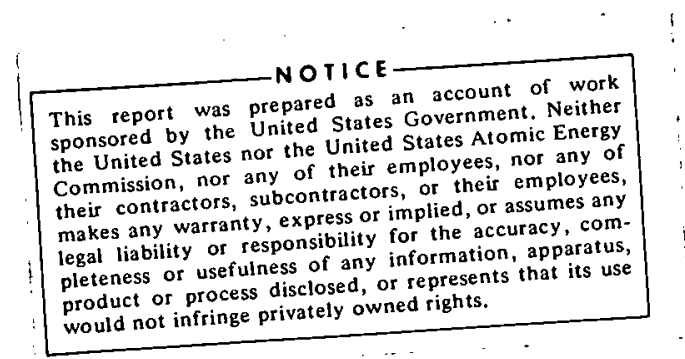

was prepared as an Government. Neither

by the United States States Atomic Energy

product or process disclosed, or represents

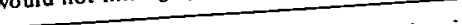




\section{DISCLAIMER}

This report was prepared as an account of work sponsored by an agency of the United States Government. Neither the United States Government nor any agency Thereof, nor any of their employees, makes any warranty, express or implied, or assumes any legal liability or responsibility for the accuracy, completeness, or usefulness of any information, apparatus, product, or process disclosed, or represents that its use would not infringe privately owned rights. Reference herein to any specific commercial product, process, or service by trade name, trademark, manufacturer, or otherwise does not necessarily constitute or imply its endorsement, recommendation, or favoring by the United States Government or any agency thereof. The views and opinions of authors expressed herein do not necessarily state or reflect those of the United States Government or any agency thereof. 


\section{DISCLAIMER}

Portions of this document may be illegible in electronic image products. Images are produced from the best available original document. 
Using mutagens on sperm and spermatids we have produced 19 chromosomal inversions in mice. The levels of radiation and chemical mutagen we used induced inversions in about 1 per cent of the animals screened. Hine-inversions have been transmitted through successive generations, and the particular frequency of first meiotic anaphase bridges manifested by each inversion remained constant. The cytological properties of first meiotic anaphase varied considerably among the inversions. Chromosomal locations of five inversions are known. Four of the five are fully viable in homozygous condition. 
Chromosomal inversions are needed for genetic studies mammals, particularly for studies in mutagenesis. Although inversions ought to be induced about as easily as translocations, inversions in experimental mammals have generally eluded investigators. Translocations, on the other hand, have been discovered and maintained in considerable numbers (Miller and Miller 1972). We think the difference in discovery is not due to a peculiarly low incidence of induction for inversions, but is due rather to the cryptic cytological and genetic properties of inversions compared with those of translocations. We have used the frequency of first meiotic anaphase bridges as an indicator of presumptive inversions in the mouse (Roderick, 1971) and reported on two inversions induced by this method (Roderick and Hawes, 1970). The method, a1though somewhat difficult, has been successful and has yielded several inversions. This report describes nineteen inversions in the mouse and provides additional information on the first two. 
MATERIALS AND METHODS

The general method has been described in our earlier reports. Now, in addition to radiation, we also have used chemical mutagens as inducing agents. Our usual procedure is to treat strain $D B A / 2 J$ males with a mutagen, mate them immediately to. strain $\mathrm{C} 57 \mathrm{BL} / 6 \mathrm{~J}$ females, and save offspring conceived within the first two weeks after treatment. Confining the screened animals to those conceived during the first two weeks assures fertilization by sperm and spermatids which are the most sensitive stages for induced dominant lethals and translocations, and probably therefore for inversions. When the male offspring are 60 days of age, one testis is removed, sectioned, and stained. A high frequency of bridges in the first meiotic anaphase is a first indicator of an induced inversion. Repeatedly we have found a low percentage of bridges, about 4 percent, in the first anaphases of males with no ancestral exposure to mutagens. The reasons for these bridges are not well understood, but this "background" frequency necessitates our using a quantitative approach to distinguish it from a higher frequency of bridges that indicate an inversion (Roderick 1971). Other useful indicators of inversions that we do not usually see in normal animals are broken anaphase bridges and telophase bridges of the first meiotic division.

Although anaphase bridges are the first indicator, it is necessary to prove existence of inversions by the concommitant appearance of other characteristics of inversions, such as reduced genetic recombination between genes located within or near the inverted segment. Presumptive inversions should also be "allelic" with a number of known gene loci in 
the chromosome. Also important with respect to bridge frequencies is the characteristic dominant effect of inversions when they are heterozygous and recessive effect when they are homozygous. Furthermore, the anaphase bridge frequency should be stable over generations for a particular inversion. Each of these characteristics has been found in one or more of the inversions uncovered by a high frequency of bridges. Because of this we feel that a significantly high frequency of first meiotic anaphase bridges (always compared sinultaneously with animals with no ancestral mutagen treatment) is sufficient to be reasonably assured of a newly induced inversion. 


\section{RESULTS AND DISCUSSION}

Rate of induction of inversions: Table 1 summarizes the results of screening for new inversions. Only nine of those found have so far been propagated beyond the original male carrier. The others were either sterile, or dead before they could be mated. Some were discarded because the inversions were presumably small. In this table, males are classified as inversion carriers if they consistently showed at least $15 \%$ anaphase bridges in repeated counts of sets of 20 anaphases. A least 40 and usually 60 or more anaphases were scored for each male which showed 3 or more bridges in the first set of 20 . Of course it is possible that an animal which really has the true background frequency of $4 \%$ bridges could by chance show a frequency of 6 or more bridges in 40 anaphases $(=1.5 \%)$ but the probability of this occurring by chance is 0.0025 . Therefore we presume that animals with at least 6 bridgesfin 40 anaphases represent something new and probably an inversion.

\section{Table 1 about here}

Roderick (1971) calculated the rate of induction of inversions of sufficient length to produce at least $11 \%$ anaphase bridges accumulating over repeated counts. This estimate for sperm and spermatids; based on a total of 541 animals with an average radiation dose of $814 \mathrm{R}$ was

$$
\begin{aligned}
& 15 / 541 / 814=3.4 \times 10^{-5} \text { per } R \text { per gamete } \\
& \text { or } 2.8 \% \text { of animals screened. }
\end{aligned}
$$

We have found that small inversions are hard to maintain because of the problem of confusing them with animals with the normal background frequency, 
and thus have settled on mating animals which have only the longer inversions giving at least $15 \%$ anaphase bridges. The data in Table 1 are all of this second kind. The induction rate for radiation is $15 / 859 / 1557=1.1 \times 10^{-5}$ per $\mathrm{R}$ per gamete or $1.0 \%$ of animals screened.

The rate is smaller and indicates, as does the array of bridge frequencies in Table 2, that longer inversions are less frequently induced than smaller ones.

In another experiment ethylmethane-sulfonate (EMS) and triethylene melamine (TEM) were administered to animals through oral and intraperitoneal routes. Preliminary experiments of Soares and Petersen (in preparation) indicate there is not a significant difference between the effects of these mutagens induced by these different routes. Assuming no difference, the animals in these experiments received an average of either $311 \mathrm{mg} / \mathrm{kg}$ of EMS or $0.19 \mathrm{mg} / \mathrm{kg}$ of TEM. An estimate of the rate of induction of inversions for EMS is therefore

$$
\begin{aligned}
& 1 / 311 / 156=2.06 \times 10^{-1} \text { per } \mathrm{mg} / \mathrm{kg} \text { TEM (I.P. or oral) per } \\
& \text { gamete of } 0.6 \% \text { of animals screened }
\end{aligned}
$$

The estimate for TEM is

$$
\begin{aligned}
& 3 / .19 / 114=1.39 \times 10^{-1} \text { per } \mathrm{mg} / \mathrm{kg} \text { TEM (I.P. or oral) per } \\
& \text { gamete or } 2.6 \% \text { of animals screened. }
\end{aligned}
$$

Flupromazine and triflupromazine were chemical mutagens used in other studies which provided us an opportunity to obtain preliminary data on their importance for inducing inversions. None were found.

It does not appear that TEM or EMS will be substantially more 
effective than irradiation in producing inversions, although TEM may be a little better. Of considerable importance, however, is the fact that two of the inversions induced by these chemicals are probably at least twice as long as the longest ones produced by irradiation. Inversion In(5) $9 \mathrm{Rk}$ induced by TEM produces in excess of $70 \%$ first meiotic anaphase bridges (Table 2). Another inversion induced by oral administration of EMS also produces a bridge frequency in excess of $70 \%$. This inversion, was observed in a male who has not as yet produced offspring.

Table 2 about here

Inversions induced: Inversions are given symbols only after the animals reproduce and we can show that their characteristic high frequency of bridges is passed to approximately half of the sons. Table 3 summarizes the data for the nine inversions which have been propagated. The inversion nomenclature is altered from that reported earlier (Roderick and Hawes, 1970; Roderick, 1971). The number in parentheses now refers to the chromosome where the inversion is located. The number after the parenthesis, as before, is the number of the inversion in the order found. The initials refer to our laboratory. This nomenclature parallels that in use for translocations of the mouse and now incorporates the use of chromosome numbers instead of linkage groups (Committee, 1972). Elsewhere in this paper we will use an abbreviated nomenclature, referring to inversions by their number only, e.g. In1, In 2 , etc.

Wherever possible at least 100 anaphases were observed for each original male showing a high frequency of bridges. This is a first approximation to the frequency of bridges we expect that particular 
inversion to manifest in heterozygous descendants. In each original male's own offspring as well as offspring from his inversion carrying descendants we obtained data on the numbers of sons showing the high frequency (inversion heterozygotes) and those showing the normal background frequency (normal homozygotes). For each of the 9 inversion stocks there was an approximately equal number of inversion carrying males and normal males. Thus the genetic transmission was as expected, and there was no indication of lesser viability of inversion carrying malẹs.

Table 3 about here

The number of anaphases to be tallied for each male descendant is determined before counting and depends on the frequency of bridges in the original male. An inversion providing between $15 \%$ and $30 \%$ bridges necessitates a count of 40 bridges to be reasonably certain of distinguishing inversion carriers from normals. Inversions manifesting between 30 and $40 \%$ bridges require only 20 anaphases, and bridges over $70 \%$ require only 10 . For each inversion we have made separate distributions showing numbers of animals on the axis and the number of percent bridges on the abscissa. Distributions for the first two inversions were reported earlier (Roderick and Hawes, 1970), and the others have been similar. The distribution for inversion In9 is shown in Figure 1, since it manifests the highest bridge frequency so far found. (For the male showing 3 bridges in the first $10(30 \%)$, sixty anaphases were scored so that we could be certain in which category he fell. The distributions for descendants of each original inversion-carrying male shows a 
similar bimodal distribution where the low modes are similar between inversions, but the high modes center around the mean of the original sire (Table 3). There is no reason to believe that the variation around the means is due to anything other than sampling error. Propagation from males anywhere in the high part of the distributions produces offspring with the characteristic frequency of that particular inversion. For the 9 inversions there is a high correlation of frequency of bridges between the original males and their own inversion carrying descendants (Tables 2 and 3). The rank order correlation which is significant at $P<0.01$ leve1 is +0.93 . Thus there is no evidence for changes in frequencies over generations.

The average background frequency, based on the percentages of the normal descendants in Table 3 is $0.042 \pm 0.002$. This is slightly higher than the 0.035 frequency we reported earlier (Roderick, 1971). Using 0.042 as the expected frequency, we found that the array of control frequencies were not homogeneous: $\chi^{2}=18.64 ; \mathrm{df}=8 ; \mathrm{P} \simeq 0.02$. Hypotheses which might explain this heterogeneity are (1) sampling error, (2) a genetic difference of some kind in the particular inversion stocks which alters the background frequency, or (3) a change in our method of counting. Even though the more recently examined inversion stocks seem to have a higher background bridge frequency, we have no reason to believe our method of discrimination or ascertainment of anaphases and bridges has altered over the course of these studies. Therefore at this time hypothesis 3 seems unlikely. We feel hypothesis 2 is the most likely if the heterogeneity is real, but this hypothesis is also not completely 
satisfying since there is much similar ancestry in most of the inversion stocks. When a satisfactory explanation is found for the background bridges, then a better hypothesis can perhaps be made for the heterogeneity. In any event, the heterogeneity is not $\operatorname{lare}_{1}^{9}$ nor of practical consequence since the general background level of $4.2 \%$ can still be differentiated from the much higher frequencies of inversion heterozygotes. The cytological characteristics of the inversions vary. The histological slides of the original inversion males were coded and read in detail. They were characterized for the number of anaphases, bridges, fragments, general bridge length, number of broken bridges, telophase bridges, and double bridges. Furthermore, the number of sections for the entire slide was noted so that the frequency of anaphases per section could be determined. Finally each bridge was characterized as to its thickness, shape, and associated lumps. We suspect that short bridges with an associated lack of telophase bridges indicate that inversions are relatively close to their centromeres. This remains to be proved. We also suspect that morphological characteristics of the bridge will be clues either to specific chromosomes involved or perhaps to relative sizes of chromosomes involved. This also must be proved. In the meantime, we have recorded these idjosyncrasies with the objective of finding meaningful associations.

For example, there is a wide variation among the inversions in the frequency of associated acentric fragments. In9 shows about one fragment for every two bridges seen, whereas only about $2 \%$ of the bridges of In2 have fragments. In 1 , In5, and In9 show a number of associated telophase 
bridges, whereas most of the other inversions produce very few telophase bridges. The bridges of In(1)IRk are consistently lumpy generally showing a lump at either end and sometimes a lump in the center. The center lump may be an attached acentric fragment, and the lumps at either end may be characteristic coilings of that particular chromosome. The bridges of In5 are also consistently lumpy, but most bridges of other inversions are thin and smooth. The bridges of $\operatorname{In} 9$ are uniformly solid in appearance not like bridges of other inversions. Bridges of In 4 and In 8 are of ten very irregular which may be a result of an associated translocation in each of those cases.

We derive an initial estimate of the length of an inversion by the percentage of anaphase bridges. If crossing over within the inversion is precisely correlated with its length, then the distance in centi-Morgans would be $1 / 2$ the frequency of anaphase bridges. There are two reasons why the length of smaller inversions may be more severely underestimated from bridge frequencies. Firstly, we do not count broken bridges as part of our count of anaphase bridges, since sometimes artifacts may also appear as broken bridges. Maximum length of a bridge before it breaks is equal to $2 A+B$, where $A$ is the distance from the centromere to the inversion and $B$ is the length of the inversion. Even though $B$ is only a fraction of this length, a smaller $B$ will lead to a greater likelihood of broken bridges. This greater likelihood reduces the true anaphase bridge frequency as we estimate it.

The second reason for underestimating the length of smaller inversions is the fact that homologous pairing between an inverted segment and its 
normal homologous segment may be less likely to occur completely in small inversions. If true, crossing over would be reduced in the segment with a corresponding reduction of apparent bridges. The best ascertainment of an inversion's effective length is estimated (1) by the loci along the chromosome with which the inversion does not recombine or (2) from the actual proportion of the inverted segment visualized by the new methods of banding chromosomes (Davisson and Roderick, 1973).

Inversion homozygotes: With respect to anaphase bridges, paracentric inversions have the peculiar genetic property of being dominant when and recessive when homozygous heterozygous. Thus, a mating of animals heterozygous for the same inversion should produce two types of sons in equal proportions, those with a high frequency of bridges and those with a normal background frequency. of those which are "normal", half can be expected to be inversion-homozygotes and the other half should be non-inversion homozygotes. We have identified inversion homozygotes in these offspring by removing one testis from each son and then outcrossing only those sons with the low background percentage of bridges. Inversion homozygotes should produce sons all of which are heterozygous and show the high bridge frequency. Normal homozygotes should produce no inversion offspring and all their sons would have the same background bridge frequency. Females which are inversion-homozygotes can be similarly identified, but there is not the initial advantage in separating them from heterozygotes by testis examination. In some cases we have had genetic markers to help in an initial separation of the presumptive inversion-homozygotes from the others. To be certain we have homozygous lines, we have checked the bridge frequencies of sample males from the lines at least every other generation, and have simultaneously 
outcrossed the males and checked bridge frequencies of their sons. Homozygous lines have been established for In1, In2, In6, and In9. Apparent1y In 4 and In8 are homozygous lethal, and In5 may possibly be lethal only in males and in most females. No attempt was made to produce homozygous lines for In 3 and In7. 


\section{ACKNOWLEDGMENTS}

This study was supported by Contract AT(11-1)-3267 with the U.S. Atomic Energy Commission, by NIH Research Grant GM-1965் from the National Institute of General Medical Sciences, and by the Eloise Dr.

and Richard Webber Foundation. We thank K. W. Petersen and E. R. Soares for permitting us to examine offspring of animals they treated with various chemical mutagens. The Jackson Laboratory is fully accredited by the American Association for Accreditation of Laboratory Animal Care. 


\section{LITERATURE CITED}

Committee on Standardized Genetic Nomenclature for Mice. 1972.

Standard karyotype of the mouse, Mus musculus. J. Hered. 63: $69-72$.

Davisson, M. T., and T. H. Roderick. 1973. Chromosomal banding patterns of two paracentric inversions in mice. (Submitted to Cytogenetics and Cel1 Genetics).

Miller, D. A., and O. J. Miller. 1972. Chromosome mapping in the mouse. Science 178:949-955.

Roderick, T. H. 1971. Producing and detecting paracentric chromosoma1 inversions in mice. Mutation Res. 11:59-69.

Roderick, T. H., and N. L. Hawes. 1970. Two radiation-induced chromosomal inversions in mice (Mus musculus). Proc. Nat. Acad. Sci. $67: 961-967$. 
TABLE 1. SCREENING FOR INVERSIONS WITH VARIOUS MUTAGENIC AGENTS.

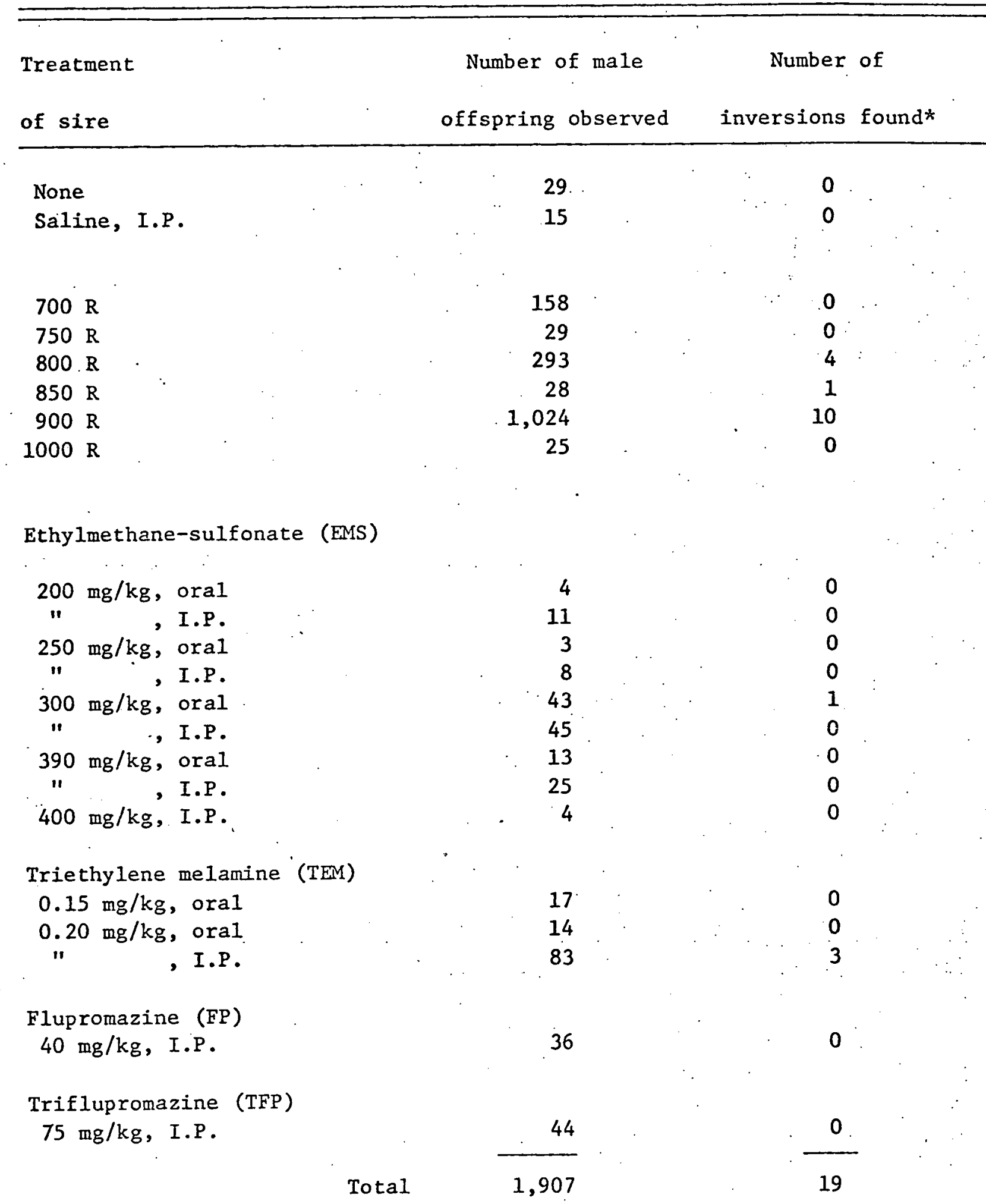

*Males are classified as inversion carriers only if they show frequencies of first meiotic anaphase bridges consistently above 15\%. A11 males screened were conceived within two weeks of treatment of their sires. 
TABLE 2. INVERSIONS INDUCED IN THE MOUSE

\begin{tabular}{|c|c|c|c|c|c|c|}
\hline Male Nंo. & $\begin{array}{l}\text { Genet1c } \\
\text { Stock* }\end{array}$ & $\begin{array}{l}\text { Inversion } \\
\text { Symbol }\end{array}$ & $\begin{array}{l}\text { Anaphaie : } \\
\text { bridge frequency }\end{array}$ & $\begin{array}{c} \pm \text { standard } \\
\text { error }\end{array}$ & $\begin{array}{l}\text { Induced } \\
\text { by }\end{array}$ & Comments \\
\hline 471 & 1 & & 0.379 & 0.033 & $800 \mathrm{R}$ & functionally sterile \\
\hline 587 & 2 & & 0.176 & 0.034 & $"$ & died before mating \\
\hline 618 & $"$ & $\operatorname{In}(1) 1 \mathrm{Rl}$ & 0.340 & 0.008 & $900: R$ & . \\
\hline 639 & $"$ & & 0.151 & 0.026 & $" \because$ & fertile, discarded \\
\hline 816 & $"$ & $\operatorname{In}(5) 2 \mathrm{Rk}$ & 0.192 & 0.010 & $850 \mathrm{R}$ & \\
\hline 2414 & $"$ & & 0.340 & 0.048 & $9900 \mathrm{R}$ & small, died \\
\hline 2425 & $"$ & & 0.158 & 0.033 & $"$ & discarded \\
\hline 2457 & $"$ & In3Rk & 0.143 & 0.016 & $"$ & $"$ \\
\hline 2576 & $"$ & & 0.164 & 0.050 & $"$ & $"$ \\
\hline 2624 & $"$ & & 0.175 & 0.050 & $"$ & $"$ \\
\hline 2913 & $"$ & In4Rk & 0.188 & 0.013 & $"$ & : \\
\hline 2916 & $"$ & $\operatorname{In}(2) 5 R k$ & 0.345 & 0.014 & $"$ & \\
\hline 3563 & $"$ & $\operatorname{In}(10) 6 \mathrm{Rk}$ & 0.262 & 0.018 & $"$ & \\
\hline 4587 & $"$ & In7Rk & 0.150 & 0.024 & $800 \mathrm{R}$ & discarded \\
\hline 4609 & $"$ & In 8Rk & 0.179 & 0.019 & $"$ & \\
\hline 5204 & 3 & $\operatorname{In}(5) 9 \mathrm{Rk}$ & 0.737 & 0.020 & $.2 \mathrm{mg} / \mathrm{kg}$ TEM I.P. & . \\
\hline 6567 & 4 & & 0.741 & 0.033 & $300 \mathrm{mg} / \mathrm{kg}$ EMS oral & \\
\hline 6845 & 5 & & 0.294 & 0.055 & $.2 \mathrm{mg} / \mathrm{kg}$ TEM I.P. & \\
\hline 6857 & $"$ & & 0.228 & 0.047 & $"$ & \\
\hline
\end{tabular}

* 1. Heterogeneous stock; male was $\underline{\mathrm{Ra}}+1+\underline{\mathrm{Sd}}$

2. $(\mathrm{C} 57 \mathrm{BL} / 6 \mathrm{~J} \times \mathrm{DBA} / 2 \mathrm{~J}) \mathrm{F}_{1}$

3. $(\mathrm{C} 3 \mathrm{H} / \mathrm{HleJ} \times \mathrm{DBA} / 2 \mathrm{~J}) \mathrm{F}_{1}$
4. $\mathrm{C} 57 \mathrm{BL} / 6 \mathrm{~J} \times(\mathrm{C} 3 \mathrm{H} / \mathrm{HeJ} \times \mathrm{DBA} / 2 \mathrm{~J}) \mathrm{F}_{1}$

5. $(\mathrm{DEA} / 2 \mathrm{~J} \times \mathrm{C} 57 \mathrm{BL} / 6 \mathrm{~J}) \mathrm{F}_{1}$ 
E 3. PERCENT OF ANAPHASE BRIDGES OF HIGH AND NORMAL DESCENDANTS OF THE ORIGINAL INVERSION-HETEROZYGOTES

\begin{tabular}{|c|c|c|c|c|c|c|}
\hline \multirow[b]{2}{*}{ Inversion } & \multicolumn{2}{|c|}{ High descendants } & \multicolumn{3}{|c|}{ Norma1 descendants } & \multirow[b]{2}{*}{$\mathrm{P}^{*}$} \\
\hline & $N \mathrm{~N}$ & Percentage & $N$ & Percenta & age & \\
\hline $\operatorname{In}(1) 1 R k$ & 155 & $1264 / 3721=33.97$ & 145 & $124 / 3480$ & $=3.56$ & 0.94 \\
\hline $\operatorname{In}(5) 2 \mathrm{Rk}$ & 48 & $273 / 1440=18.96$ & 50 & $55 / 1500$ & $=3.67$ & 0.54 \\
\hline In 3Rk & 10 & $45 / 320=14.06$ & 8 & $11 / 320$ & $=3.44$ & 0.97 \\
\hline In 4Rk & 38 & $139 / 760=18.29$ & 24 & $19 / 480$ & $=3.96$ & 0.26 \\
\hline $\operatorname{In}(2) 5 \mathrm{Rk}$ & 51 & $346 / 1020=33.92$ & 69 & $76 / 1380$ & $=5.51$ & 0.29 \\
\hline $\operatorname{In}(10) 6 \mathrm{Rk}$ & 24 & $123 / 480=25.62$ & 16 & $12 / 320$ & $=3.75$ & 0.49 \\
\hline In7Rk & 9. & $26 / 180=14.44$ & 9 & $11 / 180$ & $=6.11$ & 0.64 \\
\hline In 8Rk & 12 & $36 / 240=15.00$ & 14 & $15 / 280$ & $=5.36$ & 0.08 \\
\hline $\operatorname{In}(5) 9 \mathrm{Rk}$ & 37 & $276 / 370=74.59$ & 35 & $23 / 350$ & $=6.57$ & 0.44 \\
\hline
\end{tabular}

High and normal descendants are all offspring of inversion heterozygotes.

*P is the probability, based on a $x^{2}$ test, that the difference between the percentages of the original male and his inversion-carrying descendants is due to chance. 
Fig. 1. Per cent anaphase bridges of male descendants of male 5204. All were sons of animals heterozygous for inversion In(5)9Rk. The continuous lines intersect the expected numbers for each percentage. 


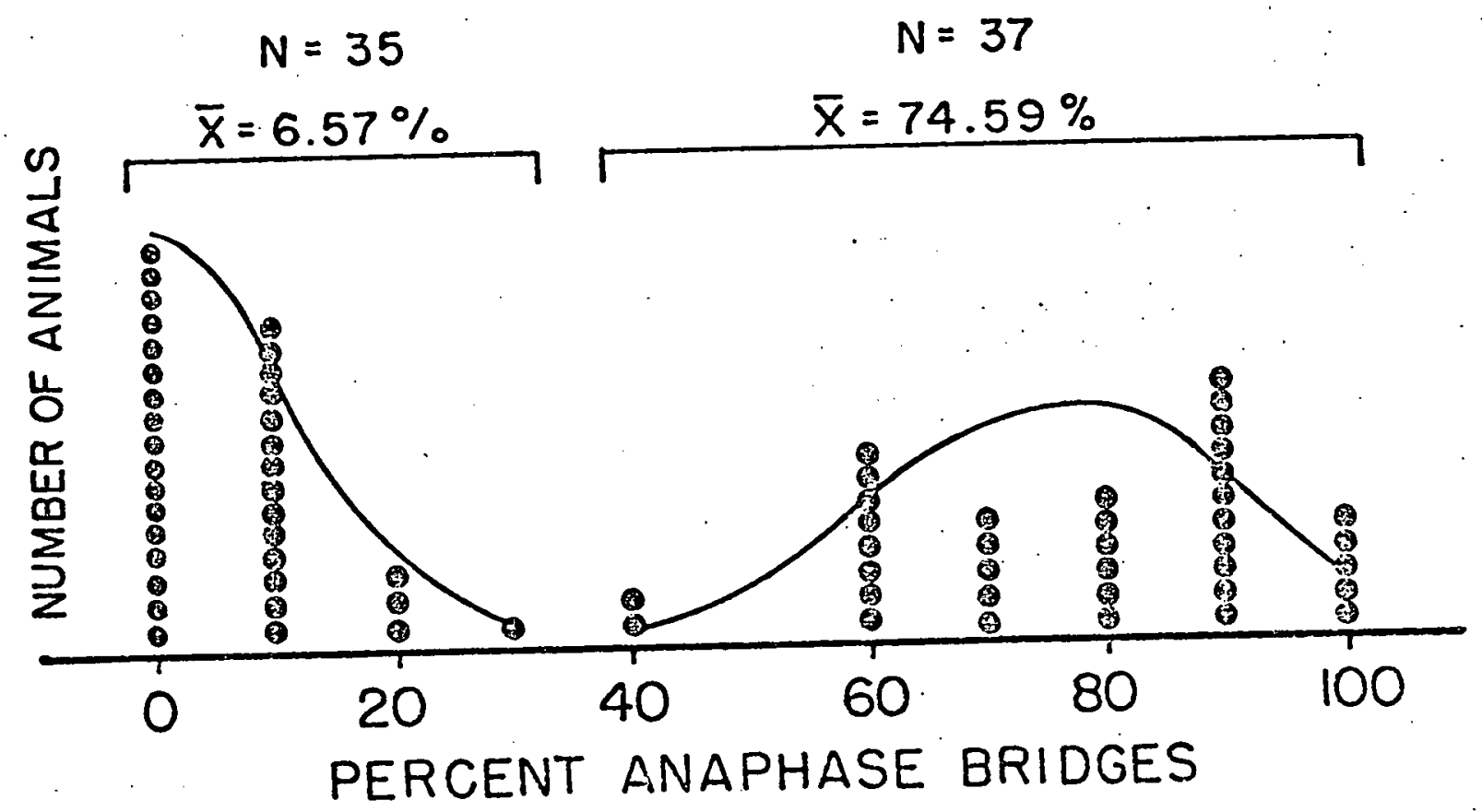

